\title{
Low levels of ionizing radiation exposure and cytogenetic effects in radiopharmacists
}

\author{
T Soltanpour Gharibdousty ${ }^{1}$, F Zakeri²,3, V Changizi ${ }^{1 *}$, MR Rajabpour ${ }^{3}$ and MR Farshidpour ${ }^{3}$ \\ ${ }^{1}$ Department of Technology of Radiology and Radiotherapy, Allied Medical Sciences School, Tehran University \\ of Medical Sciences, Tehran, Iran \\ ${ }^{2}$ Nuclear Science and Technology Research Institute, Tehran, Iran \\ ${ }^{3}$ Iran Nuclear Regulatory Authority, Tehran, Iran
}

\begin{abstract}
Radiopharmaceuticals are unique medicinal formulations containing radioisotopes which are used in major clinical areas for diagnosis and/or therapy. The aim of this study was to assess occupationally induced DNA damage in workers of a radiopharmaceutical facility who are at risk of exposure to low levels of external ionizing radiation and internal contamination. Cytokinesis-block micronucleus (CBMN) assay used as an important biological indicator of ionizing radiation exposure in the peripheral blood lymphocytes of 35 exposed workers compared with 35 controls matched for gender, age and smoking habits. Occupational dosimetry records were collected over the last year (ranged from 1.05 to $30.73 \mathrm{mSv}$ ) and last 5 years exposure (ranged from 2.56 to $70.24 \mathrm{mSv}$ ). The results showed a 2.5 fold increase in the chromosomal damage leading to micronucleated lymphocytes in the workers of the radiopharmaceutical facility compared to the controls $(25.82 \pm 8.67$ vs. $10.52 \pm 6.83$ micronuclei per 1000 binucleated cells, $p<0.0005$ ). The nuclear division index as a parameter of cytostasis, in the workers was significantly lower than that in the controls. The mean frequency of nucleoplasmic bridges was higher in the radiation workers compared to the controls without statistical significant difference $(p>0.05)$. Taking all the confounding factors into account, no obvious trend of increased micronuclei as a function of either duration of employment, exposed dose, smoking or age was observed. The present study showed that occupationally exposed individuals have higher frequencies of DNA damage, despite the very low levels of ionizing radiation exposure.
\end{abstract}

KEY WORDS: OCCUPATIONAL EXPOSURE, RADIOPHARMACIST, MICRONUCLEI, HUMAN LYMPHOCYTE

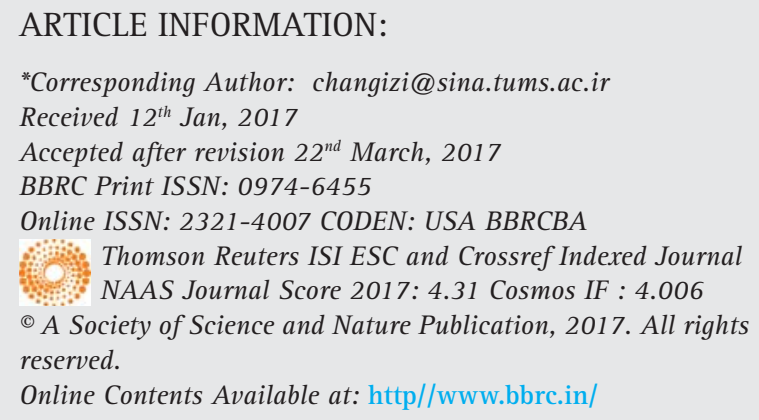


INTRODUCTION

The development of nuclear energy and the growing use of ionizing radiation in medical practice have created deep concern regarding the long-term effects of low-dose radiation on humans (Mozdarani and Samavat, 1996). Positron emission tomography (PET) is an indispensable imaging modality for the evaluation and staging of cancer patients by using radiotracers or radiopharmaceuticals, labeled with suitable positron emitting radioisotopes and necessitate special consideration in manufacturing and working knowledge of radiation safety practices is also essential. Workers in radiopharmaceutical facilities are involved in different sections of Radionuclide production and Radiopharmaceutical preparation and are at risk of external radiation exposure and internal contamination during their work, (IAEA, 2012).

Generally, monitoring of individuals occupationally exposed to ionizing radiation consists of regular film dosimetric control and periodic health examination (Zakeri et al., 2003) However, personal dosimetry may underestimate the real exposure, not only because of the detection threshold of dosimeters but also because of improper wearing (Zakeri and Hirobe, 2010, Sari-Minodier et al., 2007). Cytogenetic studies as specific biological parameters provide additional information which complements physical dosimetry and enables better evaluation of radiation exposure.The cytokinesis-block micronucleus (CBMN) assay are widely used as end points in testing for mutagens and carcinogens (Preston, 1984, Sorsa, 1990) and micronuclei (MN) induction reflects clastogenic and/or aneugenic events (Sari-Minodier et al., 2007, Zakeri and Hirobe, 2010).

MN observed in peripheral blood lymphocytes (PBL), in the first interphase after cell division, are small extranuclear bodies resulting from chromosome breaks or whole chromosomes lagging behind during anaphase. These cells can be identified as binucleated (BN) cells by addition of the cytoplasmic division inhibitor cytochalasin B during cell culture. Ionizing radiation is a strong clastogenic agent, and thus a potent inducer of MN (Vral et al., 2011).

The CBMN assay has been extensively used and validated as an appropriate bio dosimetry tool to evaluate in vivo radiation exposure of occupational, medical and accidentally exposed individuals and to assess in vitro radiosensitivity and cancer susceptibility (Sari-Minodier et al., 2007, Dias et al., 2007, Thierens and Vral, 2009). Many studies have shown that the number of radiationinduced MN strongly correlated with dose and quality of radiation. Most studies reported that MN in lymphocytes was more frequent in radiation workers than in the controls (Bonassi et al., 1997, Chung et al., 1996 and Vral et al., 2011).
In this study we examined the frequency of MN in 35 radiopharmacists occupationally exposed to ionizing radiation and 35 sex- and age-matched controls. This is important as significantly elevated levels of such aberrations may be found in peripheral blood lymphocytes of radiation workers who are exposed within the occupational limits recommended by the International Commission on Radiation Protection (ICRP and 1991.). Parameters of cell cycle progression, other biomarkers of DNA damage such as nucleoplasmic bridges and effects of confounding factors on MN induction have been also investigated.

\section{MATERIAL AND METHODS}

\section{STUDY POPULATION}

All the study population was male. The exposed group comprised 35 radiopharmacists involved in preparation and production of radiopharmaceuticals. Their age ranged from 27 to 55 years (mean of $37.59 \pm 7.22$ years) with mean employment time of $14.35 \pm 8.71$ years. The test group was routinely monitored with film badges every 2 months. Their exposure ranged between 1.05 and $30.73 \mathrm{mSv}$ (average of $6.59 \pm 5.83 \mathrm{mSv} / \mathrm{y}$ ) during the previous year and from 2.56 to $70.24 \mathrm{mSv}$ with a mean value of $17.89 \pm 15.04 \mathrm{mSv}$ during the last 5 years.

The reference control group consisted of 35 individuals, who had never been occupationally exposed to ionizing radiation or to the known carcinogenic chemicals. The controls matched the exposed subjects in age, sex and smoking habits.

All subjects in this study were questioned in detail to learn if they were systemically healthy. The questionnaire also included information about smoking habits, medical history, drug intake and diagnostic medical irradiation for all individuals. For the exposed subjects, the type, frequency and duration of occupational exposure to ionizing radiation, radiation protection measures, conditions of dosimeter wearing and work-related exposure to other hazardous agents were questioned. All the subjects were healthy individuals without current infections and medications in the last 6 months and no general or dental X-ray in the last 6 months.

The study was approved by the national ethical committee. Informed consent was obtained from each person and the study protocol conformed to the ethical guidelines of the World Medical Association (Declaration of Helsinki).

\section{Cytokinesis-block micronucleus (CBMN) assay}

Peripheral blood samples $(3 \mathrm{ml})$ were collected into sterilized lithium heparin tubes by venipuncture from each 


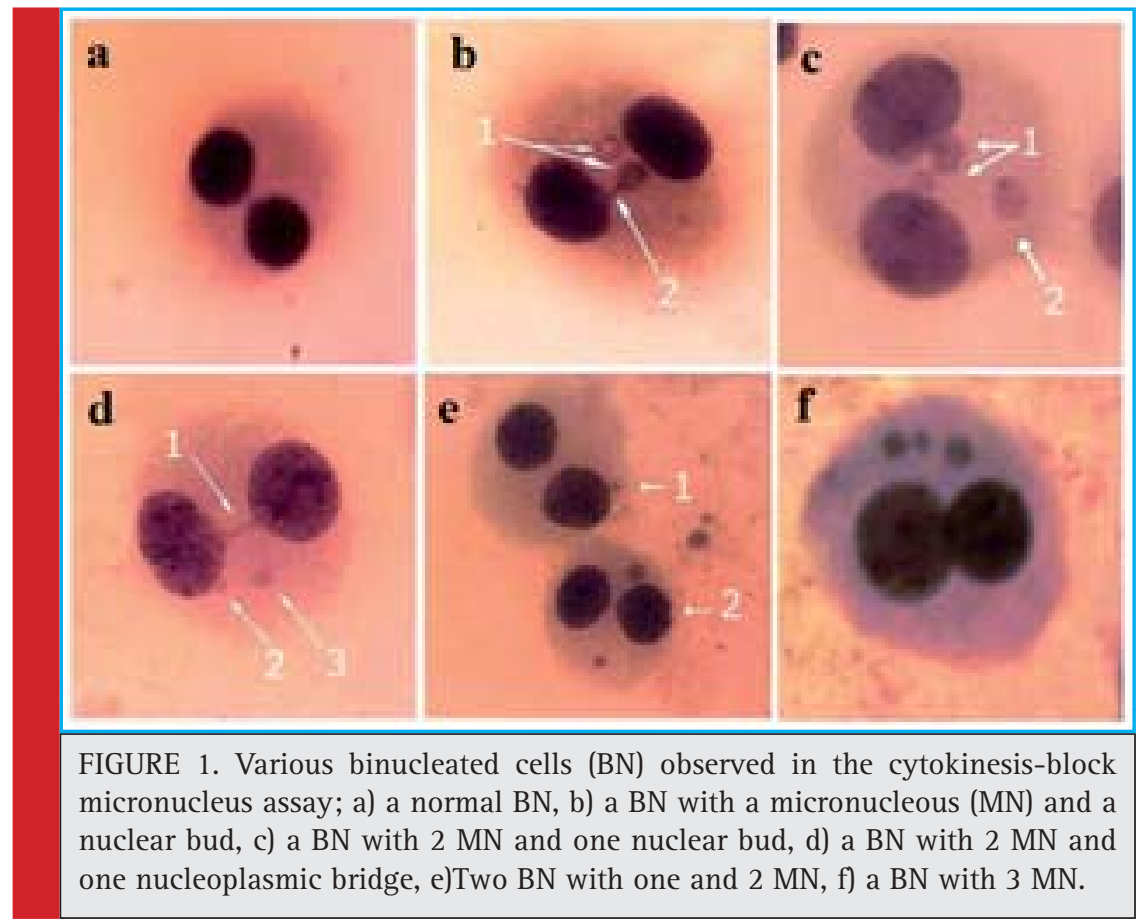

donor and all samples were coded. Whole blood cultures were created by mixing $0.5 \mathrm{ml}$ of whole blood with 4.5 $\mathrm{ml}$ of RPMI 1640 medium consisting of Ham's F10 supplemented with 20\% fetal calf serum (FCS), $100 \mathrm{U} / \mathrm{ml}$ penicillin, $100 \mathrm{mg} / \mathrm{ml}$ streptomycin, $1.0 \%$ l-glutamine and 1.0\% phytohemagglutinin (PHA) for mitogenic stimulation (all materials purchased from Gibco). The cultures were incubated at $37 \mathrm{OC}$ for $72 \mathrm{~h}$. Cytochalasin B $(6 \mathrm{mg} / \mathrm{ml})$ was added $44 \mathrm{~h}$ after culture initiation. The cells were collected by centrifugation, and treated with a mild hypotonic solution containing $0.075 \mathrm{M} \mathrm{KCl}$ for 3 min. After centrifugation and removal of the supernatant, the cells were fixed with a fresh mixture of methanol: acetic acid (3:1). Centrifugation and re-suspension were carried out three times and the cells were then dropped onto clean slides for detection of micronuclei by conventional staining with 5\% Giemsa (Zakeri and Hirobe, 2010).

MN was scored in binucleated cytokinesis-blocked cells using $400 \mathrm{X}$ magnification. The frequencies of $\mathrm{MN}$ and nucleoplasmic bridges (NPBs) were determined at the same time in binucleated cells according to the standard criteria described by Fenech (Fenech, 1993) were followed for identification of binucleated lymphocytes and MN. Figure 1 shows the various DNA damages observed in the cytokinesis-block micronucleus assay. The One thousand binucleated cells were examined for each sample. Furthermore, Cell cycle parameters were evaluated by classifying 1000 cells according to the number of nuclei. The nuclear division index (NDI) was calculated following the formula: NDI $=(\mathrm{M} 1+2 \mathrm{M} 2+$ $3 \mathrm{M} 3+4 \mathrm{M} 4) / \mathrm{n}$, where M1-M4 indicate the number of cells with 1-4 nuclei and $\mathrm{n}$ indicates the total number of

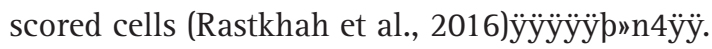

\section{STATISTICAL EVALUATION}

The frequency of MN and NDI value in the lymphocytes of the workers and controls were compared using Student's $t$ test. The influence of age, duration of employment and physical doses was tested by linear regression analysis and correlation test using SPSS, version 21 statistical program. The level of statistical significance was set at $\mathrm{p}<0.05$.

\section{RESULTS}

Demographic characteristics of control and exposed workers (radiopharmacists) are presented in Table 1. There was no difference in age and smoking status distributions between control and exposed group (Table 1).

Results of the MN, NPB and NDI frequencies have been shown in Table 2. The mean frequency of MN/1000 binucleated cells of radiation workers were significantly higher than in the control group $(25.82 \pm 8.67$ vs. $10.52 \pm 6.83, p<0.0005$, student's t-test). The mean frequency of NPBs was higher in the radiation workers compared to the controls but there was no statistically significant difference $(p>0.05)$. The mean value 
Table 1. Demographic characteristics of the radiopharmacists and the control group. Data are expressed as mean values with standard deviation.

\begin{tabular}{|c|c|c|c|}
\hline Groups & Radiopharmacists & Controls & $\mathrm{p}$ value \\
\hline $\begin{array}{l}\text { Mean age, years } \pm \text { S.D. } \\
\text { (range) } \\
\text { (no.) }\end{array}$ & $\begin{array}{l}37.59 \pm 7.22 \\
(27-55) \\
(35)\end{array}$ & $\begin{array}{l}36.98 \pm 7.44 \\
(25-55) \\
(35)\end{array}$ & 0.59 \\
\hline $\begin{array}{l}\text { Smoking habits, no. (\%) } \\
\text { Yes }\end{array}$ & $14(40.0 \%)$ & $10(28.75 \%)$ & 0.32 \\
\hline No & $21(60.0 \%)$ & $25(71.25 \%)$ & \\
\hline Mean time exposure, years \pm S.D. & $14.35 \pm 8.71$ & - & - \\
\hline $\begin{array}{l}\text { Mean last year exposure } \mathrm{mSv} \pm \mathrm{SD} \\
\text { (range) }\end{array}$ & $\begin{array}{l}6.59 \pm 5.83 \\
(1.05-30.73)\end{array}$ & - & - \\
\hline $\begin{array}{l}\text { Mean last five years exposure } m \mathrm{mv}_{ \pm} \mathrm{SD} \\
\text { (range) }\end{array}$ & $\begin{array}{l}17.89 \pm 15.04 \\
(2.56-70.24)\end{array}$ & - & - \\
\hline
\end{tabular}

of NDI; a parameter of cytostasis, for radiation workers and controls were $1.76 \pm .02$ and $1.84 \pm .03$, respectively. Although both are in the normal range, however, the NDI frequency in the control group was significantly higher than that in the workers ( $p<0.0005$, student's t-test).

The regression analysis showed no significant correlation emerged between age $(\beta=0.06, p=0.7)$, time exposure $(\beta=0.02, p=0.9)$, dose in the last year $(\beta=0.01$, $p=0.9)$ and dose in the last 5 years $(\beta=0.10, p=0.5)$ with the frequencies of the MN/1000 BN cells in the exposed workers. There were no significant differences between the mean $\mathrm{MN} / 1000 \mathrm{BN}$ cells in the smoker and nonsmoker exposed workers $(26.12 \pm 10.32$ vs., $22.0 \pm 6.22$, $\mathrm{p}=0.20$ ) and between smoker and non-smoker controls $(11.31 \pm 7.51$ vs., 9.70 $\pm 4.20, p=0.48)$ analyzed by Student's t-test.

\section{DISCUSSION}

In the present study, the CBMN assay was used to evaluate chromosomal damage in peripheral blood lymphocytes of 35 radiopharmacists working in a radiopharmaceutical facility involving in the preparation and production of radionuclides and radiopharmaceuticals in comparison with their sex- and age-matched controls.

Although the level of radiation dose received occupationally by workers was mostly below the accepted annual limit of $20 \mathrm{mSv} / \mathrm{year}$, the frequencies of MN were significantly higher in the workers than in the controls $(25.82 \pm 8.67$ vs. $10.52 \pm 6.83$ per 1000 binucleated cells, $p<0.0005)$. A relatively high frequency of MN formation in lymphocytes of radiation workers compared with non-exposed individuals might be due to an accumula-

\begin{tabular}{|c|c|c|c|}
\hline Groups & Radiopharmacists & Control & $\mathrm{p}$ value \\
\hline $\begin{array}{l}\text { Mean MN frequency }(\% 0) \pm \mathrm{SD} \\
\text { (range) } \\
\text { (no.) }\end{array}$ & $\begin{array}{l}25.82 \pm 8.67 \\
(11-48) \\
(35)\end{array}$ & $\begin{array}{l}10.52 \pm 6.83 \\
(2-23) \\
(35)\end{array}$ & $<0.0005 a$ \\
\hline $\begin{array}{l}\text { Mean NDI frequency }(\% 0) \pm \text { SD } \\
\text { (no.) }\end{array}$ & $\begin{array}{l}1.76 \pm .02 \\
(35)\end{array}$ & $\begin{array}{l}1.84 \pm .03 \\
(35)\end{array}$ & $<0.0005 \mathrm{a}$ \\
\hline Mean NPB frequency $(\% 0) \pm$ SD & $1.02 \pm 0.47$ & $0.85 \pm 0.37$ & NS \\
\hline $\begin{array}{l}\text { Mean MN frequency }(\% 0) \pm \mathrm{SD} \\
\text { Smokers (no.) } \\
\text { Non-smokers (no.) }\end{array}$ & $\begin{array}{l}27.46 \pm 9.01(14) \\
24.13 \pm 7.54(21) \\
p=0.35\end{array}$ & $\begin{array}{l}11.51 \pm 6.89(10) \\
9.54 \pm 4.21(25) \\
p=0.44\end{array}$ & \\
\hline \multicolumn{4}{|c|}{$\begin{array}{l}\text { MN: micronuclei, NDI: Nuclear division index, NPB: Nucleoplasmic bridge } \\
\text { a :obtained by Student's t-test } \\
\text { S.D: standard deviation } \\
\text { NS: not significant }\end{array}$} \\
\hline
\end{tabular}


tion of initial DNA damage in people exposed to chronic doses of radiation.

Many studies reported significantly higher MN rates in exposed population than in controls (Sari-Minodier et al., 2007, Zakeri and Hirobe, 2010). Maluf et al (Maluf et al., 2001) also reported increased frequency of MN and dicentric bridges in the lymphocytes of medical workers exposed to X-rays. These results are also in agreement with those who showed a significant higher MN values in interventional cardiologists when compared with clinical cardiologists working outside the catheterization laboratory (Andreassi et al., 2005).

Indeed age, gender and smoking habit are the most important demographic variables impacting on the MN index (Fenech, 1998). The age-related decline in the efficiency of the repair processes and the accumulation of mutations may lead to increased levels of DNA damage, which is observed by a higher frequency of chromosomal aberrations (Wojda et al., 2007).

In addition to age, gender-related changes in the level of MN frequency have been observed in many studies. Effect of gender on MN formation has been described for $\mathrm{X}$ chromosome micronucleation as being prevalent in females (Mateuca et al., 2006). According to Fenech et al (Fenech et al., 1994), an additional mechanism, possibly the loss of the $\mathrm{X}$ chromosome, accounts for the higher MN frequency in female. However, since the surveyed groups in this study were all men and the mean age was relatively the same in both groups, these effects have not been observed.

Although cytokinetic and cytostatic effects have been detected in heavy and moderate smokers (CalderonEzquerro et al., 2007), smoking habits may or may not affect the genotoxic effect of chronic radiation exposure (Maffei et al., 2002, Sari-Minodier et al., 2007, Hadjidekova et al., 2003). Bonassi et al (Bonassi et al., 2003) evaluated the impact of smoking on MN frequency using pooled re-analysis of 24 databases from the Human project. Our study indicated that smokers do not experience an overall increase in the MN frequency compared with non-smokers.

In this study, as reported by others, no association between chromosome damage and absorbed dose was found. The lack of a dose-effect relationship between chromosome damage and chronic exposure to low levels of ionizing radiation could be attributed to various factors, which can be explained by the fact that during chronic exposure part of the chromosomal damage can be eliminated in vivo by the death of lymphocytes. This can be attributed to proliferation rate of lymphocytes, inter-individual variation, elimination of aberrant cells, and lifespan of lymphocytes (Kubelka et al., 1992).

In this study the frequencies of NPBs were higher in the exposed workers than in the controls without sta- tistically significant difference $(\mathrm{p}>0.05)$. NPBs originate from dicentric chromosomes that may be caused by misrepair of double strand DNA breaks or telomere end fusions. NPBs occur when centromeres of dicentric chromosomes are pulled to opposite poles of the cell anaphase (Fenech, 2007). However, previous studies have shown that NPB is not radiation specific because it can also be induced by reactive oxygen species (Umegaki and Fenech, 2000).

NDI may be used to define cell cycle progression of the lymphocytes after mitogenic stimulation and it is a useful research tool for understanding the cell cycling kinetics of the cultures specially after radiation exposure (Rastkhah et al., 2016) ÿÿÿÿÿ-Fm4ÿÿ. Our results showed a significant decrease in the NDI values of radiation workers compared with non-exposed individuals ( $p>0.0005$ ), that could be due to the chronic low dose exposure. Significant decrease in the pooled NDI values with increasing radiation doses was also observed by other studies (Antunes et al., 2014, Pejchal et al., 2011, IAEA, 2001.).

The increased micronuclei frequencies found in exposed workers indicate potential genetic hazards that may play critical role in radiation-induced carcinogenesis and genetic diseases in long term (Zakeri and Hirobe, 2010). It has been reported that the processes of preparing and dispensing therapeutic radiopharmaceuticals have a greater potential to expose operators to radiation than do procedures for diagnosis. These operations should therefore be performed in a controlled area with entry restricted to essential staff only and careful consideration should be given to the amount of shielding required and to the measures to be taken to avoid radiation exposure from internal contamination (AGENCY, 2011).

In radiopharmaceutical facilities, the main precautions required in dealing with external irradiation will depend on the physical characteristics of the radiation emitted, the total activity and the physical half-life of the radionuclide. Contamination from unsealed radioactive substances may produce a further external radiation hazard (Radiation and Protection, 2008).Now, it is becoming increasingly clear that long-term radiationinduced cancer risk can be dramatically minimized by effective implementation of good practice of radiation protection in radiopharmaceutical facilities and 'responsibility is on all workers and professional staff to minimize the radiation exposure to themselves (Shadley et al., 1987).

Therefore, our findings suggest that radiation workers should be aware of the necessity of applying radiation protection principles (justification, optimization and limitation) and confirm that the regulatory body shall establish and enforce requirements for the protec- 
tion of workers in existing exposure situations and support services such as education and training, technical services, regular maintenance of equipment and quality control program. Furthermore, evaluation and follow-up of occupational doses should be considered as an important part of quality assurance programs. In this regard, cytogenetic monitoring, specially by using CBMN assay is a valuable tool versus fllm dosimetry following lowdose radiation exposure and for risk assessment of personnel believed to be exposed to radiation.

\section{ACKNOWLEDGMENT}

This study has been supported by Tehran University of Medical Sciences. Grant number:27610

\section{REFERENCES}

Agency, I. A. E. 2011. Radiation Protection And Safety Of Radiation Sources: International Basic Safety Standards, Vienna, International Atomic Energy Agency.

Andreassi, M. G., Cioppa, A., Botto, N., Joksic, G., Manfredi, S, Federici, C, Ostojic, M., Rubino,P. \&t Picano, E. (2005) Somatic DNA Damage In Interventional Cardiologists: A Case-Control Study. Faseb J, 19, 998-9.

Antunes, A. C., Martins, V., Cardoso, J., Santos, L. \&t Monteiro Gil, 0. (2014). The Cytokinesis-Blocked Micronucleus Assay: Dose Estimation And Inter-Individual Differences In The Response To Gamma-Radiation. Mutat Res Genet Toxicol Environ Mutagen, 760, 17-22.

Bonassi, S., Forni, A., Bigatti, P., Canevarollo, N., De Ferrari, M., Lando, C., Padovani, P., Bevegni, M., Stella, M., Vecchio, D. Et Puntoni, R. (1997). Chromosome Aberrations In Hospital Workers: Evidence From Surveillance Studies In Italy (19631993). Am J Ind Med, 31, 353-60.

Bonassi, S., Neri, M., Lando, C., Ceppi, M., Lin, Y. P., Chang, W. P., Holland, N., Kirsch-Volders, M., Zeiger, E. \&t Fenech, M. (2003). Effect Of Smoking Habit On The Frequency Of Micronuclei In Human Lymphocytes: Results From The Human Micronucleus Project. Mutat Res, 543, 155-66.

Calderon-Ezquerro, C., Sanchez-Reyes, A., Sansores, R. H., Villalobos-Pietrini, R., Amador-Munoz, O., Guerrero-Guerra, C., Calderon-Segura, M. E., Uribe-Hernandez, R. \&t Gomez-Arroyo, S. (2007). Cell Proliferation Kinetics And Genotoxicity In Lymphocytes Of Smokers Living In Mexico City. Hum Exp Toxicol, 26, 715-22.

Chung, H. W., Ryu, E. K., Kim, Y. J. \& Ha, S. W. (1996). Chromosome Aberrations In Workers of Nuclear-Power Plants. Mutat Res, 350, 307-14.

Dias, F. L., Antunes, L. M., Rezende, P. A., Carvalho, F. E., Silva, C. M., Matheus, J. M., Oliveira, J. V., Jr., Lopes, G. P., Pereira, G. A. \& Balarin, M. A. (2007) Cytogenetic Analysis In Lymphocytes From Workers Occupationally Exposed To Low Levels Of Ionizing Radiation. Environ Toxicol Pharmacol, 23, 228-33.
Fenech, M. (1993). The Cytokinesis-Block Micronucleus Technique And Its Application To Genotoxicity Studies In Human Populations. Environ Health Perspect, 3, 101-7.

Fenech, M. (1998). Important Variables That Influence BaseLine Micronucleus Frequency In Cytokinesis-Blocked Lymphocytes-A Biomarker For Dna Damage In Human Populations. Mutat Res, 404, 155-65.

Fenech, M. (2007). Cytokinesis-Block Micronucleus Cytome Assay. Nat Protoc, 2, 1084-104.

Fenech, M., Neville, S. \&t Rinaldi, J. (1994). Sex Is An Important Variable Affecting Spontaneous Micronucleus Frequency In Cytokinesis-Blocked Lymphocytes. Mutat Res, 313, 203-7.

Hadjidekova, V. B., Bulanova, M., Bonassi, S. \& Neri, M. (2003). Micronucleus Frequency Is Increased In Peripheral Blood Lymphocytes Of Nuclear Power Plant Workers. Radiat Res, 160, 684-90.

IAEA (2001). Cytogenetic Analysis For Radiation Dose Assessment, Technical Report Series 405; , Vienna, .

IAEA (2012). Radioisotopes And Radiopharmaceuticals Series No. 3, Cyclotron Produced Radionuclides: Guidance On Facility Design And Production Of Fluorodeoxyglucose (Fdg), Vienna,. ICRP (1991). Recommendations Of The International Commission On Radiological Protection.Publication 60., Pergamon, Oxford.

Kubelka, D., Garaj-Vrhovac, V. \&t Horvat, D. (1992). Chromosomal Aberrations In Persons 0ccupationally Exposed To Annual X-Irradiation Doses Lower Than 25 Msv. Journal of Radiological Protection, 12, 33.

Maffei, F., Angelini, S., Forti, G. C., Lodi, V., Violante, F. S., Mattioli, S. \& Hrelia, P. (2002). Micronuclei Frequencies In Hospital Workers Occupationally Exposed To Low Levels of Ionizing Radiation: Influence Of Smoking Status And Other Factors. Mutagenesis, 17, 405-9.

Maluf, S. W., Passos, D. F., Bacelar, A., Speit, G. Et Erdtmann, B. (2001). Assessment Of Dna Damage In Lymphocytes Of Workers Exposed To X-Radiation Using The Micronucleus Test And The Comet Assay. Environ Mol Mutagen, 38, 311-5.

Mateuca, R., Lombaert, N., Aka, P. V., Decordier, I. \&t KirschVolders, M. (2006). Chromosomal Changes: Induction, Detection Methods And Applicability In Human Biomonitoring. Biochimie, 88, 1515-31.

Mozdarani, H. \&t Samavat, H. (1996). Cytogenetic Biomonitoring Of 65 Radiology Technologists Occupationally Exposed To Chronic Doses Of X-Irradiation In Iran. Medical Journal Of The Islamic Republic Of Iran, 1, 43-46.

Pejchal, J., Vasilieva, V., Hristozova, M., Vilasová, Z., Vávrová, J., Alyakov, M., Tichý, A., Zárybnická, L., Šinkorová, Z., Tambor, V., Kubelková, K. \& Dresler, J.( 2011). Cytokinesis-Block Micronucleus (Cbmn) Assay/Cbmn Cytome Assay In Human Lymphocytes After In Vitro Irradiation And Its Use In Biodosimetry Mil. Med. Sci. Lett. (Voj. Zdrav. Listy), 80, 28-37.

Preston, R. (1984). Cytogenetic Abnormalities As An Indicator Of Mutagenic Exposure. In: Ansari Aa, De Serres Fj (Eds.), 
Single Cell Mutation Monitoring Systems, Methodologies And Applications. New York:Plenum Press,.

Radiation \& Protection (2008). Radiation Health \& Safety Advisory Council, No14.2 Series Publication.

Rastkhah, E., Zakeri, F., Ghoranneviss, M., Rajabpour, M. R., Farshidpour, M. R., Mianji, F. \&t Bayat, M. (2016). The Cytokinesis-Blocked Micronucleus Assay: Dose-Response Calibration Curve, Background Frequency In The Population And Dose Estimation. Radiat Environ Biophys, 55, 41-51.

Sari-Minodier, I., Orsière, T., Auquier, P., Martin, F. \&t Botta, A. (2007). Cytogenetic Monitoring By Use Of The Micronucleus Assay Among Hospital Workers Exposed To Low Doses Of Ionizing Radiation. Mutation Research/Genetic Toxicology And Environmental Mutagenesis, 629, 111-121.

Shadley, J. D., Afzal, V. \& Wolff, S. (1987). Characterization of The Adaptive Response To Ionizing Radiation Induced By Low Doses Of X Rays To Human Lymphocytes. Radiat Res, 111, 511-7.

Sorsa, M. (1990). Use Of Cytogenetics In Detection Of Human Exposure To Mutagens And Carcinogens In The Work Place. In: Sherma Ak (Ed.), Advance In Cytogenetics. Calcutta : Irl.
Thierens, H. \&t Vral, A. (2009). The Micronucleus Assay In Radiation Accidents. Ann Ist Super Sanita, 45, 260-4.

Umegaki, K. Et Fenech, M. (2000). Cytokinesis-Block Micronucleus Assay In Wil2-Ns Cells: A Sensitive System To Detect Chromosomal Damage Induced By Reactive Oxygen Species And Activated Human Neutrophils. Mutagenesis, 15, 261-9.

Vral, A., Fenech, M. \&t Thierens, H. (2011). The Micronucleus Assay As A Biological Dosimeter Of In Vivo Ionising Radiation Exposure. Mutagenesis, 26, 11-7.

Wojda, A., Zietkiewicz, E. \&t Witt, M. (2007). Effects Of Age And Gender On Micronucleus And Chromosome Nondisjunction Frequencies In Centenarians And Younger Subjects. Mutagenesis, 22, 195-200.

Zakeri, F., Assaei, R. \&t And Varzegar, R. (2003). Chromosomal Aberrations In Workers Occupationally Exposed To Chronic Low-Level Ionizing Radiation. Biomonitoring By Cytogenetic Analysis Of Radiation-Exposed Workers 9, 33-38.

Zakeri, F. \& Hirobe, T. (2010). A Cytogenetic Approach To The Effects Of Low Levels Of Ionizing Radiations On Occupationally Exposed Individuals. Eur J Radiol, 73, 191-5. 